\title{
enabled, a dosage-sensitive suppressor of mutations in the Drosophila Abl tyrosine kinase, encodes an Abl substrate with SH3 domain-binding properties
}

\author{
Frank B. Gertler, ${ }^{1,3}$ Allen R. Comer, ${ }^{3}$ Jyh-Lyh Juang, Shawn M. Ahern, Michael J. Clark, \\ Eric C. Liebl, ${ }^{2}$ and F. Michael Hoffmann ${ }^{4}$ \\ McArdle Laboratory for Cancer Research and Laboratory of Genetics, University of Wisconsin Medical School, Madison, \\ Wisconsin 53706 USA
}

\begin{abstract}
Genetic screens for dominant second-site mutations that suppress the lethality of $A b l$ mutations in Drosophila identified alleles of only one gene, enabled (ena). We report that the ena protein contains proline-rich motifs and binds to Abl and Src SH3 domains. ena is also a substrate for the Abl kinase; tyrosine phosphorylation of ena is increased when it is coexpressed in cells with human or Drosophila Abl and endogenous ena tyrosine phosphorylation is reduced in $A b l$ mutant animals. Like $A b l$, ena is expressed at highest levels in the axons of the embryonic nervous system and ena mutant embryos have defects in axonal architecture. We conclude that a critical function of Drosophila $\mathrm{Abl}$ is to phosphorylate and negatively regulate ena protein during neural development.
\end{abstract}

[Key Words: enabled; Drosophila; Abl tyrosine kinase; SH3 domain; tyrosine phosphorylation]

Received December 16, 1994; revised version accepted Jänuary 30, 1995.

The Abelson family of nonreceptor protein-tyrosine kinases (PTKs) consists of the mammalian c-abl and c-arg genes, Drosophila $A b l$ and caenorhabditis elegans $A b l$ (Wang 1993). The proteins have well-conserved SH3, $\mathrm{SH} 2$, and kinase catalytic domains and are distinguished from the src family of nonreceptor tyrosine kinases by a large ( 600-amino-acid) domain carboxy-terminal to the kinase domain. Several functions have been attributed to this carboxy-terminal region including nuclear localization (Van Etten et al. 1989), DNA binding (Kipreos and Wang 1992), F-actin and G-actin binding (Van Etten et al. 1994), SH3-domain binding (Feller et al. 1994; Ren et al. 1994), and, in Drosophila, localization of the protein to axonal processes in the developing nervous system /Henkemeyer et al. 1988). Mammalian c-Abl displays both cytoplasmic and nuclear localization /Van Etten et al. 1989; Wang 1993) in fibroblasts, although it is reported to be primarily cytoplasmic in hematopoietic cells (Wetzler et al. 1994). RNA polymerase II (Baskaran et al. 1993) and the c-crk adapter protein (Feller et al. 1994; Ren et al. 1994) have been reported to be substrates for the c-Abl PTK, and recent studies have identified asso-

\footnotetext{
Present addresses: ${ }^{1}$ Fred Hutchinson Cancer Research Center Seattle, Washington 98104-2092 USA; ${ }^{2}$ Department of Biology, Denison University, Granville, Ohio 43023 USA.

${ }^{3}$ These authors have contributed equally to this work and are considered first authors.

${ }^{4}$ Corresponding author.
}

ciations between c-Abl and crk (Feller et al. 1994; Ren et al. 1994) and between C-Abl and Rb (Welch and Wang 1993). However, it is as yet unclear how important these interactions are for Abl-mediated signaling.

Much of the interest in the Abl PTK stems from the involvement of oncogenically activated derivatives of the c-Abl PTK in Philadelphia chromosome-positive chronic myelogenous leukemia (CML) and acute lymphocytic leukemia (ALL) in humans and the pre-B-cell leukemia caused by Abelson murine leukemia virus in mice. The Philadelphia chromosome translocations generate fusions between the c-abl and $b c r$ genes (Shtivelman et al. 1985; Ben-Neriah and Baltimore 1986). The chimeric protein products of these oncogenes exhibit elevated tyrosine kinase activity (Kloetzer et al. 1985; Konopka et al. 1985), oligomerization and association with the actin cytoskeleton (McWhirter and Wang 1991, 1993), tyrosine phosphorylation of Bcr sequences (Liu et al. 1993), and association with GRB2 (Pendergast et al. 1993; Puil et al. 1994), Shc (Matsuguchi et al. 1994; Puil et al. 1994), cbl (Andoniou et al. 1994), Syp (Tauchi et al. 1994), and members of the 14-3-3 protein family (Reuther et al. 1994).

The function of $\mathrm{c}-\mathrm{Abl}$ in mammalian development is as yet unclear. Recent studies suggest that c-Abl in the nucleus can negatively regulate proliferation of fibroblasts in culture (Sawyers et al. 1994). Targeted disruptions of $\mathrm{c}-a b l$ in the mouse causes perinatal lethality 
with no obvious phenotypic abnormalities (Schwartzberg et al. 1991; Tybulewicz et al. 1991). Null mutations in Drosophila also cause late lethality after development of the adult fly during metamorphosis (Henkemeyer et al. 1987). The observation that loss of Drosophila Abl function does not result in more severe defects earlier in development suggests that the absence of Abl function can be partially compensated for by redundant functions (Hoffmann 1991).

Screens for second-site mutations that interact genetically with $A B I$ in flies have identified mutations in three genes [disabled (dab), prospero (pros), or failed axon connections (fax)] whose products are in part responsible for masking the function of Drosophila $A b l$. Whereas $A b l$ mutant animals die at the end of pupation, flies that lack $A b l$ function and have only one copy of $d a b$, fax, or pros die during embryonic or larval stages (Gertler et al. 1989, 1993). When mutations are used to remove these functionally redundant proteins, the roles of the Abl PTK in axonogenesis of the embryonic central nervous system (CNS) and in the formation of muscle attachment sites are revealed. For example, $A b l$ mutant embryos that also lack $d a b$ display defects in the axonal architecture of the embryonic CNS and in body wall muscle attachments (Gertler et al. 1989, 1993; Bennett and Hoffmann 1992). Presumably, similar mechanisms of functional redundancy mask more severe effects of the $c-a b l$ null mutations in the mouse.

To gain further insight into the normal functions of a member of the Abl PTK family, we have screened for second-site modifier mutations that suppress the lethality of $A b l$ mutations in Drosophila. We have recovered mutations in only one gene, which we have named enabled (ena). Although $A b l$ mutant animals die at the end of pupation or as young adults, flies that lack $A b l$ function and have only one copy of the ena gene survive to adulthood with no obvious defects /Gertler et al. 1990). Heterozygous ena mutations also largely restore normal axonal patterning in embryos mutant for $A b l$ and $d a b$. (Gertler et al. 1990). The observation that a reduction in the level of ena compensates for the absence of $A b l$ activity suggests that these two molecules normally function in opposition to one another in a precise balance.

We have cloned the ena gene and report that it encodes a novel protein with several proline-rich SH3 binding motifs. Bacterially expressed ena protein is bound by the GST-AblSH3 and GST-SrcSH3 proteins in filter-binding assays but not by several other GST-SH3 domain fusion proteins. The ena protein contains phosphotyrosine in vivo and is phosphorylated by the Drosophila or human Abl PTK when coexpressed in Drosophila cultured cells. Of particular interest is the observation that the level of phosphotyrosine on endogenously expressed ena is reduced in $A b l$ mutant animals. As would be consistent for an in vivo Abl substrate, ena protein is colocalized with $A b l$ in the axons of the embryonic CNS. Mutations in ena cause defects in the axonal architecture of the CNS and peripheral nervous system (PNS) including misrouted axons and loosely packed bundles of axons. On the basis of these genetic and biochemical properties, we propose that phosphorylation of ena by $\mathrm{Abl}$ regulates the function of ena during axonogenesis and that this is a key physiological role of the Abl PTK in Drosophila.

\section{Results}

\section{Molecular cloning of ena and sequence analysis}

Previous studies had mapped ena to the 55F-57A region of the Drosophila chromosomes (Gertler et al. 1989, 1990). To localize the gene more precisely, $\gamma$-rays were used to induce cytologically visible chromosomal aberrations in the ena locus. Nine new ena alleles were recovered in this screen, and five of these mutations caused visible rearrangements that affected 56B5 (Fig. 1A). We obtained a P-element insertion at this location from Dr. Gerald M. Rubin (University of California, Berkeley), and flanking genomic DNA was recovered by plasmid rescue. The rescued fragment was used to begin a chromosome walk in which $54 \mathrm{~kb}$ of DNA from the 56B region was isolated (Fig. 1A). Chromosomal rearrangements in ena mutants were identified with probes from the walk, with three inversion and one translocation breakpoints all recognized by a single $5.5-\mathrm{kb}$ probe (Fig. 1A, fragment A). This $5.5-\mathrm{kb}$ fragment was used to isolate cDNAs from an embryonic cDNA library (Brown and Kafatos 1988), the longest of which was $3.4 \mathrm{~kb}$. Southern analyses showed that the cDNA spanned the same rearrangement breakpoints mapped on the walk (data not shown), indicating that the $3.4-\mathrm{kb}$ cDNA represented the ena transcript.

The lethality caused by en a mutations was prevented by expression of this cDNA in the CNS of developing ena mutants, confirming that this cDNA is the product of the ena gene. This was accomplished using the GAL4 binary expression system (Brand and Perrimon 1993). Several transgenic lines were recovered of independent insertions of a P-element transgene in which the ena cDNA was expressed under the control of the yeast GAL4 upstream activating sequence (UAS). Flies from these different transgenic lines of $\mathrm{P}\left[U A S-e n a, \mathrm{w}^{+}\right]$were mated to flies expressing GAL4 in all neuronal cells. The GAL4 expression was the result of an enhancer-trap insertion of a GAL4-encoding P-element transgene la gift of Dr. Andrea Brand, Wellcome/CRC Institute, Cambridge, UK). Progeny in which the endogenous ena gene was mutant died unless they inherited both the $\mathrm{P}[U A S-$ ena, $\left.\mathrm{W}^{+}\right]$transgene and the GAL4 transgene. The neuralspecific expression of ena from the transgene allowed $60 \%$ of the expected progeny class to survive as fertile flies without detectable phenotypic abnormalities (not shown). Although the lethal phase of the other $40 \%$ of the progeny class is not known, the incomplete rescue may be attributable to differences between endogenous expression levels or patterns and those generated by the GAL4 binary expression system.

Sequencing of the ena cDNA revealed an open reading frame of 684 amino acids with a predicted molecular mass of $72 \mathrm{kD}$ (Fig. 1B). Searches of the GenEMBL and 


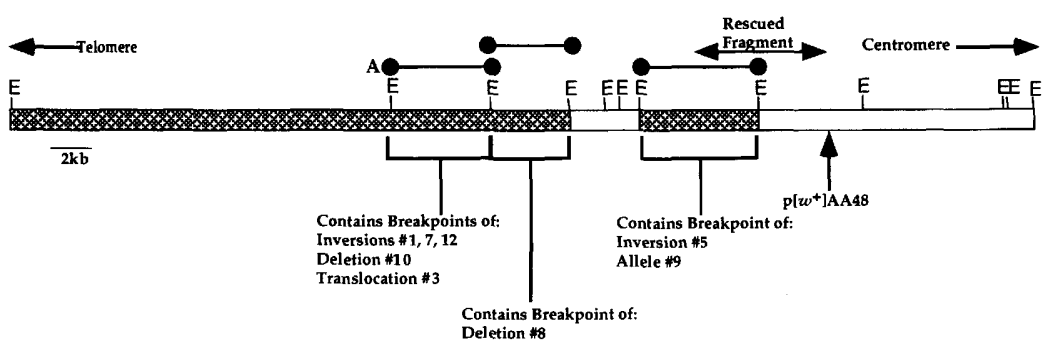

B

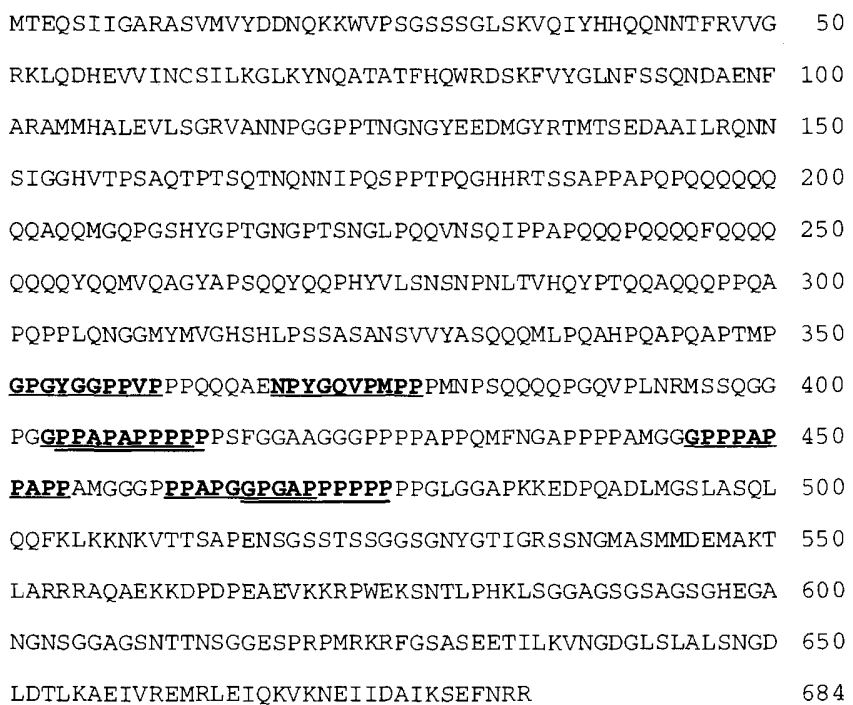

Figure 1. Chromosomal rearrangements affecting the ena locus. (A) An EcoRI restriction map of a $54-\mathrm{kb}$ region of DNA containing the ena gene. $(\uparrow)$ The insertion site of a P element (AA48). This transposon was used to recover $7 \mathrm{~kb}$ of genomic DNA (horizontal arrow) that was used to initiate a chromosomal walk. Stippled regions hybridized to ena cDNA probes. Brackets beneath the diagram indicate the positions of deletion and rearrangement breakpoints associated with $\gamma$-ray-induced ena mutations. Probe A is a $5.5-\mathrm{kb}$ DNA fragment that detected rearrangement breakpoints in ena alleles and was used to screen the cDNA library. $(B)$ Predicted amino acid sequence of the ena protein. The 684-amino-acid sequence encoded by the ena cDNA is shown. Underlined are seven matches to a consensus sequence shown to mediate binding the c-abl SH3 domain (Ren et al. 1993).
SWISS-PROT data bases identified no proteins with significant similarity to ena. The most notable feature of the predicted ena protein was a proline-rich core, with 58 proline residues located between amino acids $340-480$ and seven matches to the proline-rich consensus site for binding the Abl SH3 domain (Ren et al. 1993; underlined in Fig. 1B).

\section{ena encodes an SH3-binding protein}

The presence of sequences in ena similar to those shown to mediate binding to the c-Abl SH3 domain suggested that ena might also interact with $\mathrm{SH} 3$ domains. An ena fusion protein containing amino acids 53-503 of ena was bound by the murine c-Abl and Src SH3 domains (Fig. 2A). In contrast, this ena protein was not bound by GST (Fig. 2A) or by the SH3 domains of Crk, Gap, Nck, or GRB2 (not shown). A fusion protein (amino acids 53441; Fig. 2B) lacking the carboxy-terminal three proline motifs from ena was also bound by the c-Abl and Src SH3 domains, whereas ena fusion proteins lacking all seven matches to the $\mathrm{SH} 3$ binding consensus (amino acids 53345 and 53-235) failed to interact with either $\mathrm{SH} 3$ do- main (Fig. 2A). These results indicated that sequences responsible for the interaction with the c-Abl and Src SH3 domains are contained in the proline-rich core of ena.

\section{ena contains phosphotyrosine in vivo}

Two ena protein isoforms of $\sim 80$ and $100 \mathrm{kD}$ were detected in Drosophila S2 cells and pupae (arrows in Fig. $3 \mathrm{~A}$, left panel), whereas only the $80-\mathrm{kD}$ form was detected in embryo extracts (Fig. 3A, lanes 2,5). Both polypeptides were immunoprecipitated by antibodies recognizing two different regions of the ena protein. Neither ena protein was immunoprecipitated with preimmune antisera (not shown). The $100-\mathrm{kD}$ form was less abundant than the $80-\mathrm{kD}$ form and was most readily detected in immunoprecipitates from S2 cells (Fig. 3A). The 80$\mathrm{kD}$ isoform may correspond to the protein shown in Figure 2, as expression of the cDNA in S2 cells resulted exclusively in the synthesis of the $80-\mathrm{kD}$ isoform (Fig. 4A, lane 2). Both ena isoforms contained phosphotyrosine, as determined by antiphosphotyrosine Western blots of ena immunoprecipitates (Fig. 3A, right panel). 
Figure 2. Interaction of ena with $\mathrm{c}-\mathrm{Abl}$ and Src SH3 domains. (A) 100 or $10 \mathrm{ng}$ of ena fusion proteins containing seven (amino acids 53-503), four (amino acids $53-441$ ), or no (amino acids $53-345$ or 53 235) matches to the c-Abl-SH3-binding consensus were immobilized on nitrocellulose filters and incubated with GST (right), GST-AblSH3 (left), or GST-SrcSH3 (center) fusion proteins. Bound GST-SH3 fusion proteins were detected with antiGST antibodies (Pharmacia). Both the Abl and Src SH3 domains bound ena fusion proteins containing amino acids 53-503 and 53-441 of ena, but neither SH3 domain bound to proteins containing amino acids 53-345 or 53-235. (B) Schematic of the ena protein showing the regions used in the $\mathrm{SH} 3$-binding assays. Arrows indicate the positions within ena of sequences that match the consensus for c-Abl SH3 binding (Ren et al. 1993). The positions of truncations used in the SH3-binding experiments shown in $A$ are indicated relative to these potential SH3-binding sites.

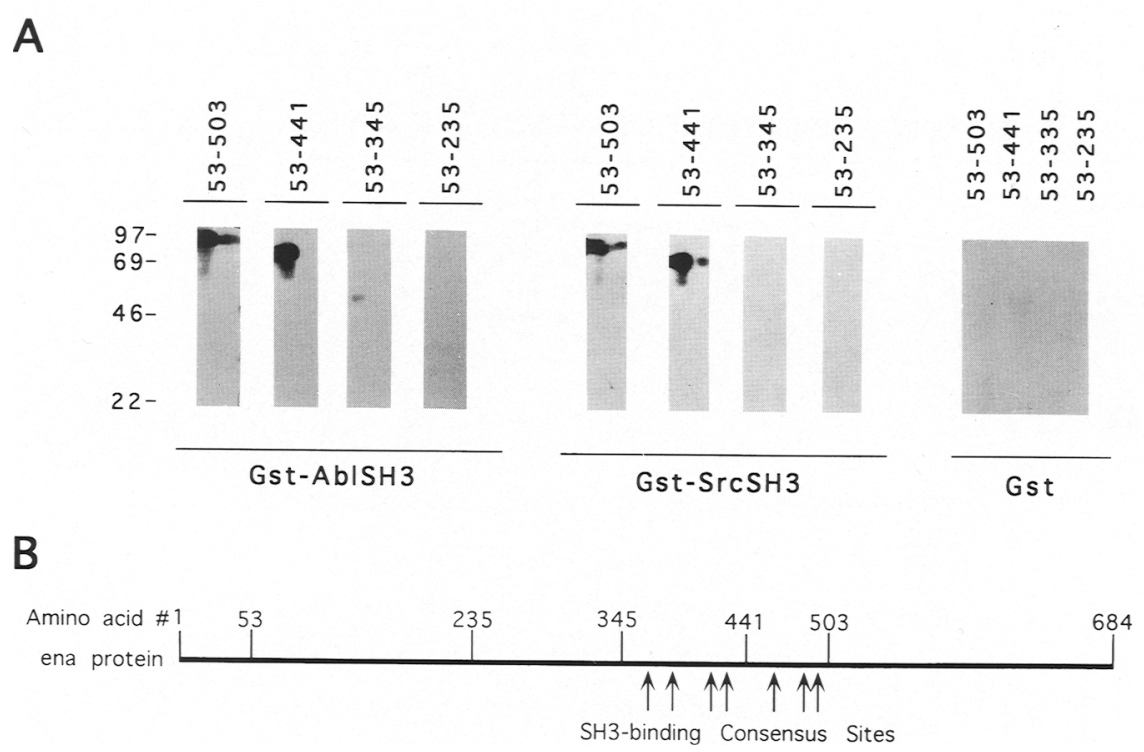

Phosphoamino acid analysis indicated that the $80-\mathrm{kD}$ ena isoform was phosphorylated predominately on serine, with lower levels of threonine and tyrosine phosphorylation (Fig. 3B).

Although the $100-\mathrm{kD}$ protein was much less abundant than the $80-\mathrm{kD}$ isoform in S2 cells, the two ena isoforms were recognized at similar levels by an antiphosphotyrosine antibody (Fig $3 \mathrm{~A}$, right panel, lanes 1,4$)$. This observation suggested that the $100-\mathrm{kD}$ form was phosphorylated on tyrosine to a higher stoichiometry than the $80-\mathrm{kD}$ species. The molecular basis for the different mobilities of the two isoforms is not known. Treatment with potato acid phosphatase eliminated antiphosphotyrosine reactivity from the $100-\mathrm{kD}$ isoform but did not alter its mobility (not shown). This suggested that the difference in mobility between the $100-$ and $80-\mathrm{kD}$ ena polypeptides was not the result of hyperphosphorylation. All of the ena cDNAs recovered thus far correspond to the sequence in Figure 1; so if alternatively spliced forms exist, they were not well represented in the embryonic cDNA library used in these experiments. We expect that the $100-\mathrm{kD}$ form is the result of a splicing event that is more prevalent in S2 cells than embryos or pupae. Because the $80-\mathrm{kD}$ ena protein is the most abundant form and this form is able to prevent the lethality caused by ena mutations, we have focused the current study on this ena isoform.

\section{ena is a substrate for $A b 1$}

To address whether the phosphotyrosine on ena could be added by the Abl PTK, we examined whether Abl could phosphorylate ena in transfected Drosophila S2 cells. Antiphosphotyrosine Western blots of ena protein im- munoprecipitated from cells transfected with ena and $\mathrm{Abl}$ indicated that ena became heavily phosphorylated when expressed with the wild-type Abl kinase (Fig. 4A, upper panel, lane 4). In contrast, ena contained much less phosphotyrosine when expressed alone (Fig 4A, lane 2) or when cotransfected with a catalytically impaired Abl kinase (K417N; Fig. 4A, lane 6). The direct phosphorylation of ena in immune complex kinase assays by $\mathrm{Abl}$ protein immunoprecipitated from S2 cells (Fig. 4C) suggested that phosphorylation of ena in transfected cells was not the result of a kinase cascade triggered by Abl. However, an additional test that the phosphorylation of ena by $\mathrm{Abl}$ is direct will require mapping and comparing the phosphorylation sites in the in vitro kinase reaction with the ena phosphorylation sites used in vivo. Coexpression of ena and human c-Abl also resulted in phosphorylation of ena, although at levels below that seen with Drosophila Abl (Fig. 4A, lane 8). Drosophila Srcl also phosphorylated ena in transfected cells (Fig. 4A, lane 12), although the increased levels of Srcl expression also resulted in the phosphorylation of a number of cellular proteins (Fig. 4B, lane 12).

Several observations suggested that the phosphorylation of ena by Abl was specific. First, the increased expression of $\mathrm{Abl}$ after transfection resulted in only a slight increase in phosphotyrosine content of S2 cells (Fig. 4B, lanes 3,4$)$. This indicated that whereas most cellular proteins were not good substrates for Abl, ena was efficiently phosphorylated by Abl. Second, two other molecules that interact genetically with $\mathrm{Abl}$ (fax and dab) were not hyperhosphorylated when coexpressed with Abl (data not shown). Finally, coexpression of ena and the Drosophila Fer PTK did not result in increased phosphorylation of ena (Fig. 4A, lane 14), demonstrating that 
A

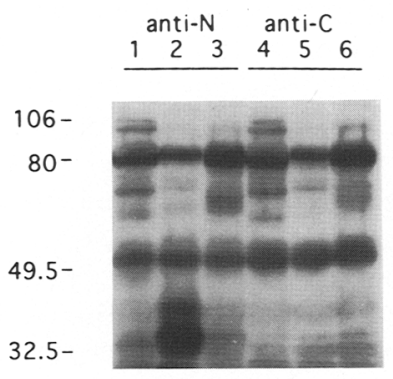

anti-ena
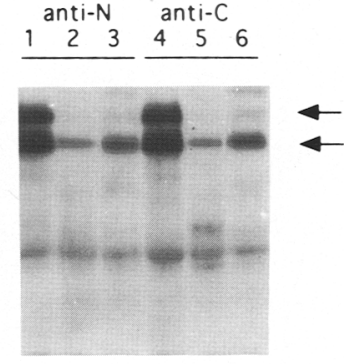

anti-ptyr

B

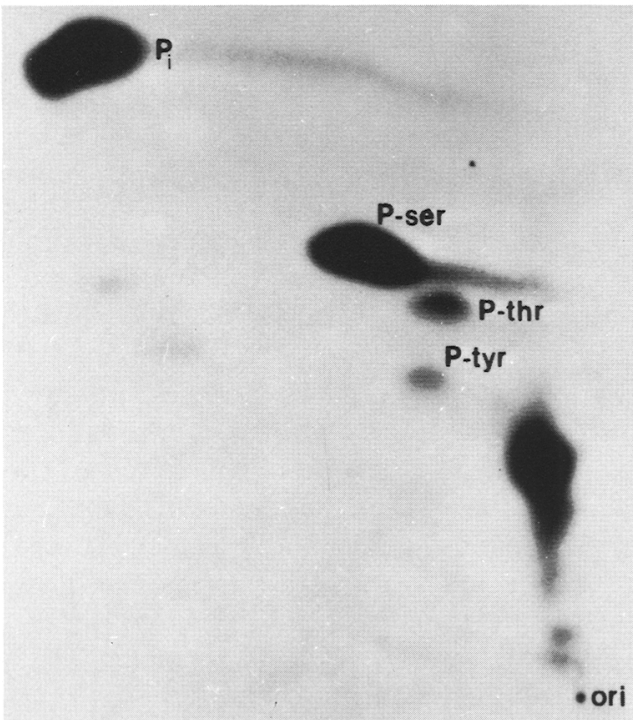

Figure 3. ena from culture cells, embryos, and pupae contains phosphotyrosine. $(A)$ ena protein was immunoprecipitated from Drosophila S2 cells (lanes 1,4), 2- to 16-hr wild-type embryos (lanes 2,5), or wild-type pupae (lanes 3,6) with anti-ena aminoterminal term (lanes 1-3) or anti-ena carboxy-terminal (lanes 4-6) antibodies. Blots were probed with anti-ena amino-terminal (left) or antiphosphotyrosine (right) antibodies. Arrows indicate the positions of $100-$ and $80-\mathrm{kD}$ ena proteins in the immunoprecipitates. Neither protein was immunoprecipitated with preimmune antisera (not shown). The immunoglobulin heavy chain from the antibody used in the immunoprecipitations is seen in all lanes just above the $49.5-\mathrm{kD}$ marker. $|B|$ Phosphoamino acid analysis of ${ }^{32} \mathrm{P}$-labeled ena protein from S2 cells shows that ena contains phosphoserine (P-ser), phosphothreonine (P-thr), and phosphotyrosine (P-tyr). Hydrolysates of $80-\mathrm{kD}$ ena protein labeled with ${ }^{32} \mathrm{P}$ in vivo were resolved by two-dimensional thin-layer electrophoresis (Cooper et al. 1983). The positions of unlabeled phosphoamino acid standards added to the samples and detected with ninhydrin following electrophoresis, as well as ${ }^{32} \mathrm{P}$-labeled inorganic phosphate $\left(\mathrm{P}_{\mathrm{i}}\right)$, are indicated.

ena is not nonspecifically phosphorylated by all nonreceptor tyrosine kinases.

To determine if the interaction between the Abl SH3
A
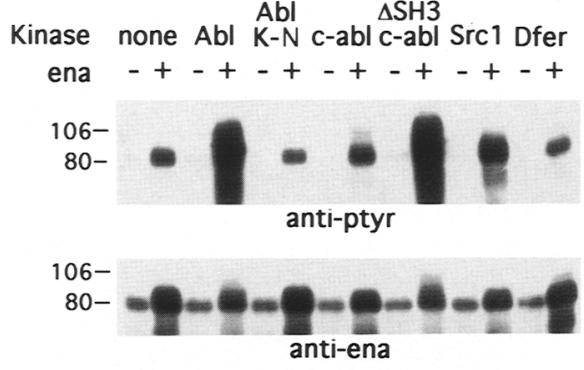

B
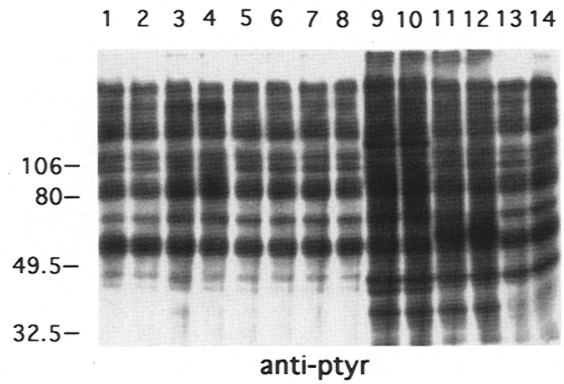

C

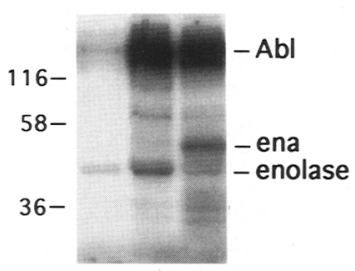

Figure 4. Phosphorylation of ena by the Abl PTK in transfected cells. S2 cells were transfected with the indicated kinases in the absence or presence of ena. (Lanes 1,2) No transfected kinase; (lanes 3,4) DAbl; (lanes 5,6) kinase defective DAbl (K417N); (lanes 7,8) human c-Abl; (lanes 9,10) human c-Abl lacking the SH3 domain; (lanes 11,12) Drosophila Srcl; (lanes 13,14) Dfer. (A) ena immunoprecipitates from transfected cells were probed with antiphosphotyrosine monoclonal antibody 4G10 (top). ena became hyperphosphorylated when expressed with DAbl (lane 4), $\triangle$ SH3-c-Abl (lane 10), Srcl (lane 12), and to a lesser extent by wild-type c-Abl (lane 8). The same filter reprobed with anti-ena $\mathrm{N}$ term $\mathrm{Ab}$ (bottom) shows that comparable levels of ena were expressed in all samples transfected with ena (even-numbered lanes). The level of endogenously expressed ena protein is shown in the odd-numbered lanes. (B) Total cell lysates from transfected cells probed with antiphosphotyrosine antibody 4G10 show the increased level of phosphotyrosine-containing proteins in cells transfected with $\triangle \mathrm{SH} 3 \mathrm{c}-\mathrm{Abl}($ lanes 9,10) and Srcl (lanes 11,12). Cells expressing DAbl (lanes 3,4 ) have only a slight increase in phosphotyrosine content as compared with untransfected cells (lane 1). (C) Immune complex kinases assays containing $5 \mu \mathrm{g}$ of acid-denatured enolase as an exogenous substrate. A reaction containing immunoprecipitated Abl (lane 2) showed autophosphorylation of $\mathrm{Abl}$ and enolase as compared with a preimmune immunoprecipitation (lane 1). Addition of 5 $\mu \mathrm{g}$ of bacterially expressed ena (amino acids 53-503) to the reaction (lane 3) resulted in phosphorylation of ena and reduction in the phosphorylation of enolase. The positions of phosphorylated $\mathrm{Abl}$, ena, and enolase are indicated at right. 
domain and proline-rich sequences in ena was necessary for phosphorylation of ena, we examined the ability of a c-Abl variant that lacked the SH3 domain to phosphorylate ena. $\Delta \mathrm{SH} 3-\mathrm{c}-\mathrm{Abl}$ phosphorylated ena in transfected cells (Fig. 4A, lane 10), indicating that Abl could phosphorylate ena in the absence of an SH3-dependent Ablena interaction. However, $\Delta \mathrm{SH} 3-\mathrm{c}-\mathrm{Abl}$ displayed elevated kinase activity that resulted in the promiscuous phosphorylation of numerous cellular proteins (Fig. 4B, lanes 9,10$)$. This observation raised the possibility that the hyperphosphorylation of ena by $\Delta \mathrm{SH} 3-\mathrm{c}-\mathrm{Abl}$ was the result of this nonspecific kinase activity.

To test further the hypothesis that the phosphorylation of ena by $\mathrm{Abl}$ requires interaction between ena and the Abl SH3 domain, truncations of the ena protein that remove portions of or all of the proline-rich region were assayed for their ability to serve as Abl substrates in S2 cells. Truncated ena proteins containing four, (amino acids 1-440), one (amino acids 1-375), or none (amino acids 1-345) of the matches to the Abl SH3 binding consensus were all hyperphosphorylated when coexpressed with Drosophila Abl but not when expressed alone (Fig. 5, left, lanes 3-81. While full-length ena contained detectable levels of phosphotyrosine in the absence of exogenous kinase (Fig. 5, left, lane 1), little antiphosphotyrosine reactivity was observed on the ena truncations in the absence of exogenously added Abl (Fig. 5, left, lanes $3,5,7)$. This apparent difference is probably the result of higher expression levels of full-length protein as compared with the truncations (Fig. 5, right, cf. lanes 1,3,5, and 7). These results indicate that when both the ena substrates and the Abl PTK are overexpressed, an interaction between the $\mathrm{Abl} \mathrm{SH} 3$ domain and the proline-rich motifs in ena was not required for efficient phosphorylation of ena.

\section{en a tyrosine phosphorylation is reduced in Abl mutants}

To determine whether endogenous ena was phosphorylated by Abl during normal development, we compared the state of ena phosphorylation in pupae that were heterozygous or homozygous for $A b l$ mutations. The level of phosphotyrosine on ena was reduced two- to threefold, but not eliminated, in animals that lacked Abl kinase activity as compared with pupae that had one wild-type $A b l$ gene (Fig. 6). Four different combinations of $A b l$ mutations were examined. This reduction in ena phosphorylation was not the result to a global reduction in tyrosine phosphorylation in $A b l$ mutants, as demonstrated by the comparable levels of phosphotyrosine-containing proteins in total lysates from these samples (Fig. 6, right). The observation that ena still contains some phosphotyrosine in $A b l$ mutants indicates that other kinases must also phosphorylate ena in the absence of Abl PTK activity. Although Drosophila Srcl phosphorylated ena in transfected cells (Fig. 4, lane 12), the phosphorylation state of ena was unchanged in Src1 mutant pupae (data not shown). This result indicates that the residual phosphorylation seen on ena from $A b l$ mutant pupae is likely to be the result of phosphorylation by kinases other than Srcl.

\section{Expression of en a during embryogenesis}

Polyclonal antibodies to the amino-terminal region of ena were used to examine the temporal and spatial pattern of ena expression during embryogenesis (Fig. 7). No maternal ena protein was detected in unfertilized eggs or early stage embryos (not shown). Expression of ena protein was first detected during germ-band extension at stage 10 and by stage 11 was detected in the endoderm and ectoderm of the extended germ band (Fig. 7A). During germ-band retraction, ena protein became restricted to the CNS and by stage 15 was observed primarily in the commissural and longitudinal axons of the CNS (Fig. 7B). During late embryogenesis (stage 17), ena protein was localized primarily to the longitudinal axons (Fig. 7C). No ena expression was observed in ena mutant embryos (Fig. 7D), confirming that these antibodies specifically recognized the ena protein.

\section{CNS and PNS defects in ena mutant embryos}

Mutations in ena result in embryonic lethality with no gross developmental abnormalities (Gertler et al. 1990). Because of the CNS expression of ena, we sought to determine whether subtle defects in CNS development
Figure 5. Phosphorylation of truncated ena proteins by $\mathrm{Abl}$ in transfected cells. S2 cells were transfected with constructions expressing either fulllength ena protein (lanes 1,2) or carboxy-terminal truncations producing proteins of 440 (lanes 3,4), 375 (lanes 5,6), or 345 (lanes 7,8 ) amino acids in the presence or absence of $\mathrm{Abl}$. The locations of the potential SH3-binding domains relative to these truncations are diagrammed in Fig. 2B. Immunoprecipitates of the ena proteins were probed with either antiphosphotyrosine (left) or anti-ena $\mathrm{N}$ term (right) antibodies. All ena proteins were hyperphosphorylated when coexpressed with $\mathrm{Abl}(+)$ but not when expressed alone $(-)$. The positions of the full-length and ena truncation proteins are indicated at right. The ena truncations migrate near the antibody used for the immunoprecipitations.

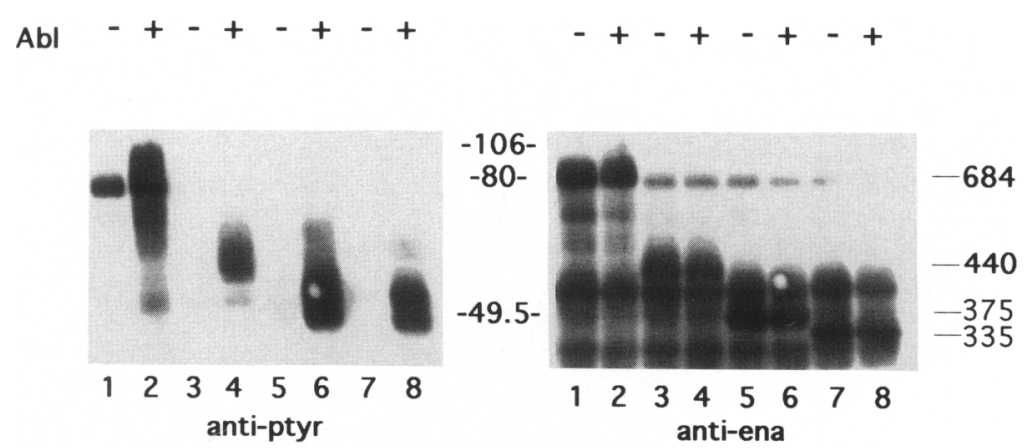



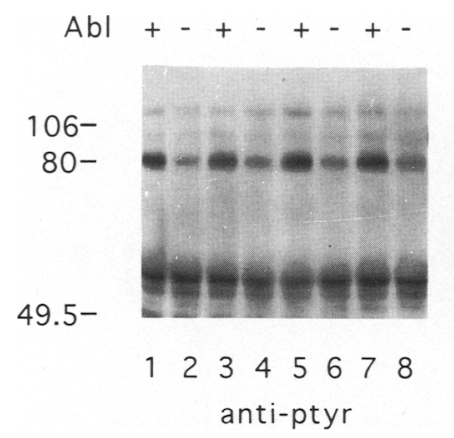

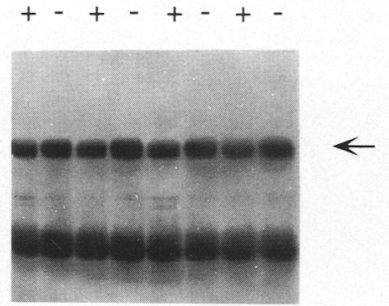

anti-ena

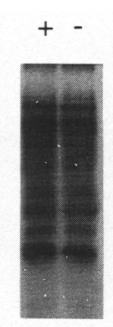

anti-ptyr

(lysates)

Figure 6. Reduced phosphotyrosine content of ena in $A b l$ mutants. An antiphosphotyrosine blot (left) of ena immunoprecipitates from pupae heterozygous or homozygous for $A b 1$ mutations showed that ena contained less phosphotyrosine in $A b I$ mutants. The intensity of phosphotyrosine reactivity in ena was determined by scanning densitometry of serial dilutions to determine a linear range for quantification. Genotypes of the samples are as follows: (Lane 1) $A b I^{4} /+$; (lane 2) $A b l^{4} / \mathrm{Df}(3 \mathrm{~L})$ e36; (lane 3) $A b 1^{4} /+$; (lane 4) $A b 1^{4} / \mathrm{Df}(3 \mathrm{~L})$ sti7; (lane 5) $A b 1^{2} /+$; (lane 6) $A b 1^{2} / \mathrm{Df}(3 \mathrm{~L})$ e36, (lane 7) $A b 1^{2} /+$; (lane 8) $A b 1^{2} /$ Df(3L) stj7. (Center) The same blot probed with antiena amino-terminal antibodies shows that comparable to levels of ena protein was immunoprecipitated from all samples. (Right) Total phosphotyrosine content in lysates from $A b l$ homozygous mutants $\left(A b 1^{2} / \mathrm{Df}(3 \mathrm{~L}) \mathrm{e} 36\right)$ is not reduced as compared with lysates from $A b l$ heterozygotes $\left.(A b)^{2} /+\right)$.

might exist in ena mutants. Embryos mutant for ena were stained with the monoclonal antibody BP102 to detect the CNS axons. Three different combinations of ena mutant alleles displayed similar CNS axonal defects. The most frequent CNS defect observed in ena mutant embryos was a reduction in the integrity of axon bundles (Fig. 8B). Whereas the longitudinal and commisural axon tracts of wild-type embryos consist of tightly associated axon bundles (Fig. 8A), the axons of ena mutants were more diffuse and less tightly bundled (Fig. 8B-D). In addition, axon misrouting was also observed in $12 \%$ of en $a^{G C 5} /$ ena $^{G C 8}$ embryos (Fig. 8B). About one-fourth to one-third of all mutant embryos showed less obvious phenotypes, such as thinning of the longitudinal connectives (arrow in Fig. 8C), increased numbers of axons exiting the CNS from the longitudinal axons /arrowheads in Fig. 8D), or the failure of commissural axons to separate into anterior and posterior axon bundles (Fig. 8C). A cross section through ena mutant nerve cords revealed a defasciculation of BP102-stained axon bundles as compared with a wild-type embryo (Fig. 8, cf. E and F).
The monoclonal antibody $22 \mathrm{C} 10$ also revealed defects in the PNS of ena mutant embryos. The PNS of a wildtype embryo consists of regularly spaced neuronal cells connected by stereotypical axon pathways (Fig. 8G). In ena mutant embryos, the overall organization of the PNS was disrupted (Fig. $8 \mathrm{H}$ ). The spacing and organization of the PNS neurons was not as regular as in wild-type, and in some cases clusters of neurons were mislocalized (arrowhead in Fig. $8 \mathrm{H}$ ). Finally, some defects in axon guidance were apparent, with axons crossing between PNS elements in adjacent segments (arrow in Fig. 8H). These defects indicate a role for the ena protein in the organization of the embryonic PNS and CNS.

\section{Discussion}

Many proteins are phosphorylated by PTKs, but in general it has been difficult to demonstrate the importance of these substrates in a biological process mediated by the PTK. We have taken a genetic approach in Droso-
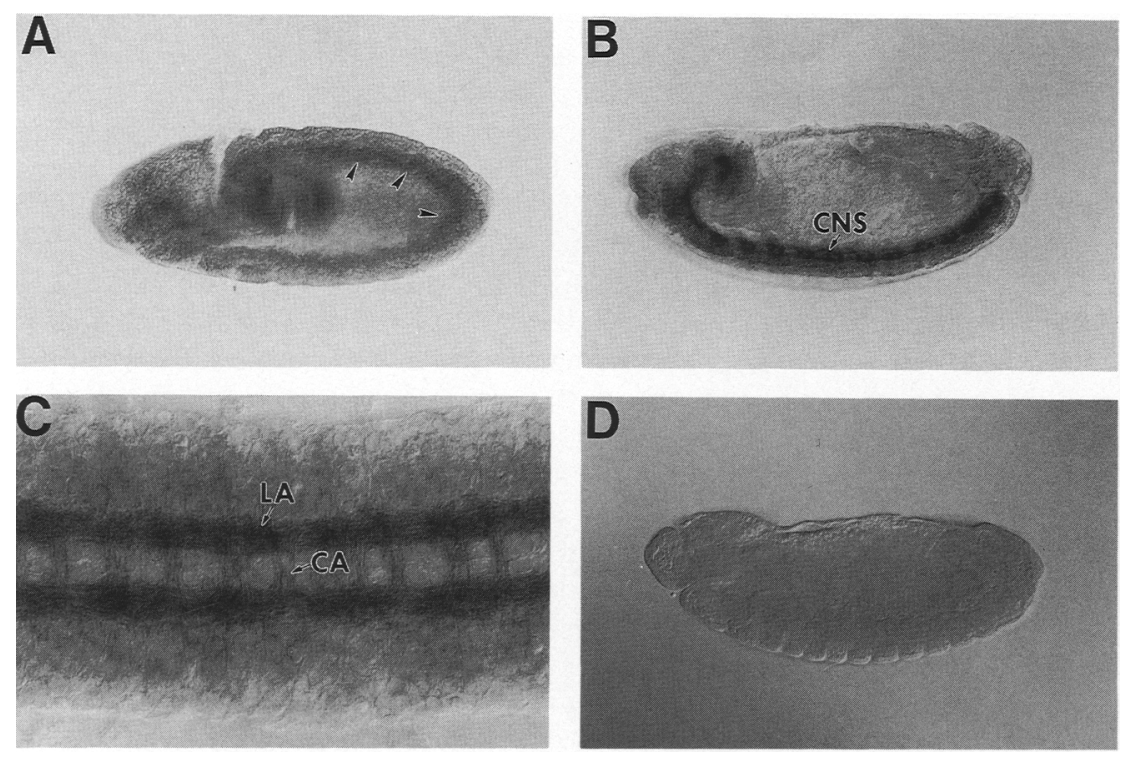

Figure 7. Expression of ena protein in wild-type embryos. Wild-type $(A-C)$ or ena mutant embryos $(D)$ were stained with affinity-purified anti-ena amino-terminal antibodies as described (Patel et al. 1987). Staging was determined by examination of CNS and gut morphology. (A) A stage 11 wild-type embryo showing ena expression in the extended germ band (arrowheads). (B) A stage 15 wild-type embryo showing ena expression restricted to the CNS near the end of germ-band retraction. $(C)$ Dissected nerve cord from a stage 17 wild-type embryo showing ena expression in the longitudinal (LA) and commissural (CA) axon bundles. Expression is also seen in the cell bodies of the CNS. (D) A stage 15 ena ${ }^{G C 1 /}$ ena ${ }^{G C 8}$ embryo showing no staining as compared with the comparably staged wild-type embryo in $B$. 
Figure 8. CNS and PNS defects in ena mutant embryos. Embryos in $A-F$ were stained with BP102 to detect CNS axons. The embryos shown in $G$ and $H$ were stained with $22 \mathrm{Cl}$, which detect PNS neurons. (A) A dissected nerve cord from an ena $a^{G C 1}$ heterozygous embryo shows a typical arrangement of longitudinal and commissural axon bundles. $|B-D|$ Nerve cords from ena mutant embryos display CNS defects including: misrouting of axon bundles (ena $a^{G C 5} / e n a^{G C 8}$; open arrow in $B$ ), thinning of longitudinal axon bundles $\left(e n a^{G C 1} / e^{e n a^{G C 8}}\right.$; arrow in $\left.C\right)$, and increased numbers of axons exiting the CNS (ena $a^{G C 1} / e n a^{C C 8}$; arrowheads in $D$ ). Cross section through a wild-type embryo $(E)$ shows tightly bundled longitudinal axons (arrows). A similar section through an ena mutant embryo $(F)$ shows the diffuse nature of longitudinal axons. $(G)$ PNS of a wild-type embryo showing the regular arrangement of dorsal, lateral, and ventral sensory organs. The abdominal segments $\mathrm{a} 1, \mathrm{a} 5$, and $\mathbf{a} 6$ are labeled for reference. $(H)$ The PNS of ena mutants is poorly organized, with mislocalized cell bodies (arrowhead in al) and axon misrouting (arrow in a6).
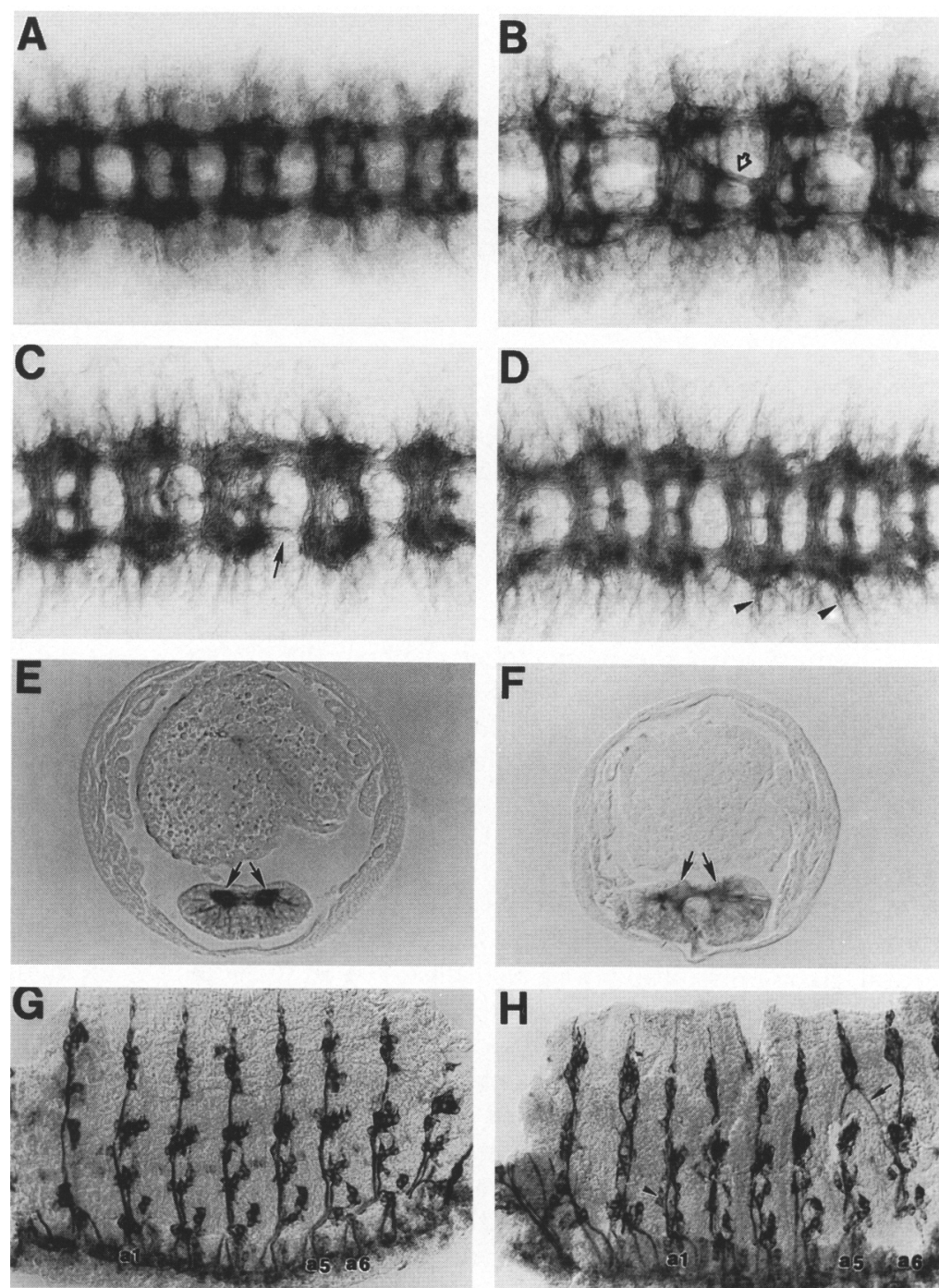

phila to identify proteins on the Abl-mediated pathway by functional criteria. ena was identified by such functional criteria in a genetic screen for dominant secondsite suppresser mutations that alleviate the lethality caused by mutations in the Abl PTK. The ena mutations recovered are loss-of-function mutations that reduce the gene dosage of ena from two functional copies to one copy and presumably reduce the level of active ena protein by $50 \%$. The observation that $A b l$ mutant flies that would usually die as young adult flies or as fully formed adults in the pupal case survive when the level of ena protein is reduced by half suggests that a normal function of $\mathrm{Abl}$ is to negatively regulate the activity of ena, presumably by phosphorylation of ena. Furthermore, a balance between the levels of $\mathrm{Abl}$ and ena activity appears to be required for normal development, which suggests that $\mathrm{Abl}$ and ena have opposite actions on some developmental process.

The best candidate for this developmental process is the formation of axonal connections in the nervous system. In the embryo, both proteins are expressed at highest levels in the axons of the developing nervous system and mutations in both genes are associated with defects in the embryonic axonal architecture. Abl's role in axonal development has been revealed by removing functionally redundant genes such as fasciclin $I$. The role of fasciclin I as a cell-adhesion molecule and the defects in axonal pathfinding in $\mathrm{Abl}$, fas I mutant embryos has implicated $\mathrm{Abl}$ in the regulation of axonal cell adhesion (Elkins et al. 1990). The importance of Abl kinase activity in development is also masked by the functions of the genes $d a b$, pros, and fax. When this functional redundancy is eliminated by mutations in these genes, development of the axonal architecture of the nervous system is disrupted, revealing a role for $\mathrm{Abl}$ in this process. In embryos mutant for both $A b l$ and $d a b$, there is a general failure to form axon bundles in the embryonic CNS (Gertler et al. 1989, 1993). Normal axonal connections 
are largely restored by kinase-active $\mathrm{Abl}$ or by a reduced level of ena, whereas kinase-defective Abl protein has no detectable effect. Therefore, reduced levels of ena can have effects similar to addition of kinase-active $\mathrm{Abl}$ in a background with mutations in both $A b l$ and $d a b$.

The Abl PTK in Drosophila also has a structural function that is independent of kinase activity. We have reported previously that the $A b l$ mutant lethality is rescued by a kinase-defective form of the $\mathrm{Abl}$ protein in which the invariant lysine in the catalytic domain is mutated to asparagine (Henkemeyer et al. 1990). This kinase-independent structural role of $\mathrm{Abl}$ requires proper subcellular localization to the axons of the developing CNS, and sequences in the domain carboxy-terminal to the kinase domain are necessary for this localization. Reduction in the level of ena compensates for the absence of this proposed structural role of $\mathrm{Abl}$ by rescuing the $A b l$ mutant lethality as effectively as the presence of the kinase-defective protein. To understand the molecular mechanisms by which ena interacts with the $\mathrm{Abl}$ signaling pathways, we have characterized the ena protein and discovered two interesting properties-binding to SH3 domains and phosphorylation by the Abl PTK.

The binding of the Abl SH3 domain to ena suggests several models for ena function. One model to explain the opposing actions of $\mathrm{Abl}$ and ena would have ena as a negative regulator of $\mathrm{Abl}$ and other PTKs that are functionally redundant to Abl. Reducing ena would allow more kinase activity from the redundant PTKs and compensate for the absence of Abl kinase activity. The presence of the proline motifs in ena provides a molecular mechanism by which ena could act as a negative regulator, that is, by binding to the $\mathrm{SH} 3$ domain of the redundant kinases. Negative regulation of the c-Abl PTK has been proposed to be mediated by interactions between the c-Abl SH3 domain and an unidentified cellular factor (Pendergast et al. 1991). Although ena can bind to the murine $\mathrm{Abl}$ and Src SH3 domains in vitro, we have no evidence that the presence of ena reduces $\mathrm{Abl}$ or $\mathrm{c}-\mathrm{Abl}$ kinase activity as indicated by Abl or c-Abl autophosphorylation in S2 cells (data not shown). Because of its inability to affect $\mathrm{Abl}$ autophosphorylation, ena is unlikely to be the Drosophila homolog of the proposed negative inhibitor of mammalian c-Abl. Although ena protein did reduce the level of enolase phosphorylation by $\mathrm{Abl}$ in vitro, this effect may be the result of simple competitive inhibition by a better substrate. The possibility remains, however, that ena may negatively regulate in vivo another $\mathrm{SH} 3$-containing kinase that is functionally redundant to $\mathrm{Abl}$.

SH3 domain-dependent interactions are important in the recruitment of some tyrosine kinase substrates. For example, the binding of the SH3 domain of crk to proline-rich sequences in c-Abl facilitates phosphorylation of crk (Feller et al. 1994; Ren et al. 1994). The SH3 domain of Src also appears to be required for efficient phosphorylation of a subset of Src substrates /Weng et al. 1994). We considered the possibility that the proline motifs on ena might function to bind to the $\mathrm{Abl} \mathrm{SH} 3$ domain to present ena for phosphorylation. However, we ob- served that truncated ena proteins lacking most or all of the proline-rich region were still phosphorylated by $\mathrm{Abl}$ when overexpressed in transfected cells. In addition, we have not detected association between $\mathrm{Abl}$ and ena in immunoprecipitates of either protein. However, other SH3 domain-binding interactions have not allowed coimmunprecipitation of the two proteins; for example, although proline-rich motifs in Btk mediate an interaction with the Fyn SH3 domain in vitro and in the yeast two-hybrid system, this interaction was not detected by coimmunoprecipitation from cells expressing both proteins (Cheng et al. 1994). If Abl and ena do associate in Drosophila, the interaction may be too transient or the affinity too low to survive immunoprecipitation.

The second property of ena reported here, its phosphorylation by Abl, suggests alternative models for ena function. An obvious role for the phosphorylation of ena is to provide sites through which ena can interact with specific SH2 domains. In this model, ena would function as an adapter molecule and the interaction of ena with $\mathrm{SH} 2$ domain-containing proteins would be regulated by phosphorylation of ena by Abl and other PTKs. There may be multiple sites of tyrosine phosphorylation on ena because, in $A b l$ mutant animals, the level of phosphotyrosine on ena was reduced but not eliminated. This is consistent with the existence of at least one other PTK capable of phosphorylating ena. It will be important to determine whether there are specific tyrosine phosphorylation sites on enabled at which the level of phosphorylation is reduced in $A b l$ mutant animals and to determine whether these are the same residues phosphorylated by $\mathrm{Abl}$ in vitro. Different sites of phosphorylation could provide ena with the ability to interact with different $\mathrm{SH} 2$ domains. We think it unlikely that the $\mathrm{SH} 2$ domain of Abl interacts with phosphorylated ena, as none of the tyrosines in ena lie within sequences similar to those bound by the Abl SH2 domain (Songyang et al. 1993). By binding to ena, SH2-containing proteins would be brought into proximity to the $\mathrm{SH} 3$ domain-containing proteins bound to the ena proline motifs. The multiple proline-rich motifs in ena could provide separate sites for binding different $\mathrm{SH} 3$ domains or could enhance SH3domain binding by providing a high local concentration of proline-rich motifs. The binding of ena to SH2- and/or SH3-containing proteins could facilitate the assembly of signaling complexes involved in axon outgrowth or pathfinding.

Binding of ena to $\mathrm{SH} 3$ domain-containing proteins could be important for the subcellular distribution of ena, as SH3 domains are known to direct the subcellular localization of signaling molecules (Bar-Sagi et al. 1993). The subcellular localization of the Abl PTK is important for its function in Drosophila axonogenesis (Henkemeyer et al. 1990), and it is likely that subcellular localization of ena is also important for its interactions with $\mathrm{Abl}$. Interactions involving SH3 domains are also important in subcellular localization and protein-complex assembly during signal transduction. For example, association of proline-rich sequences in Sos with the SH3 domains of Drk (the Drosophila homolog of GRB2) brings 
the Sos protein into proximity with Ras and leads to the activation of Ras (Olivier et al. 1993; Simon et al. 1993).

The observation that the state of occupancy of adjacent $\mathrm{SH} 2$ or SH3 domains can affect ligand binding of the other domain (Panchamoorthy et al. 1994) suggests a third model in which Abl-phosphorylated ena would associate with different SH3-SH2-containing proteins than unphosphorylated ena. ena's interactions with these target proteins could regulate their activity. For example, the GTPase activity of dynamin is activated when dynamin is bound by the $\mathrm{SH} 3$ domains of Grb2, Src, Fgr, and Fyn (Gout et al. 1993). In addition, PI-3 kinase displays elevated catalytic activity when bound to the SH3 domains of Lyn or Fyn (Pleiman et al. 1994).

The models of ena as an adapter molecule or regulator must take into account the genetic interactions between $A b l$ and ena. Because reduced levels of ena compensate for the absence of $\mathrm{Abl}$, we propose that Abl phosphorylation of ena would provide a negative regulatory effect on ena function. For example, if ena protein stimulates the activity of an enzyme, Abl phosphorylation of ena would reduce the ability of ena to bind to and activate that enzyme. The absence of Abl would lead to hyperactivation of the enzyme by unphosphorylated or underphosphorylated ena; reduction in the level of ena protein might compensate and restore a normal level of enzyme activity. Therefore, it may be more accurate to consider the effect of $A b l$ mutations as leading to a hypophosphorylation of ena tyrosines rather than the complete elimination of ena phosphorylation.

We propose that interactions between ena and other unidentified proteins are involved in the dynamic processes of cell adhesion and/or cytoskeletal changes required for optimal axonal outgrowth or fasciculation. The identification of $\mathrm{SH} 3$ domain- and $\mathrm{SH} 2$ domain-containing proteins other than Abl that bind to ena during neural development in Drosophila is a goal of ongoing experiments. Further analysis of ena function and its molecular mechanisms of action in Drosophila should provide additional insights into the cell biology of axonal outgrowth, pathfinding, and fasciculation.

The identification of ena as a biologically important substrate of the Drosophila Abl PTK raises the possibility that a similar protein exists in mammals. A murine gene encoding a protein closely related to ena has recently been identified (F.B. Gertler, P. Soriano, and F.M. Hoffmann, unpubl.). Analysis of this murine protein to determine whether it is the mammalian counterpart of ena and to ascertain whether it interacts biochemically or functionally with the mammalian c-Abl PTK could provide new information about processes that are regulated by $\mathrm{c}-\mathrm{Abl}$ and that are perturbed by oncogenically activated $\mathrm{Abl}$ proteins in mammalian systems.

\section{Materials and methods}

$\gamma$-ray mutagenesis and cytological mapping of ena alleles

Isogenic adh pr cn males were irradiated with 4500 rads and crossed en masse to $S p / C y O$; TM2 $U b x / T M 6 B, T b$ virgin fe- males for 2 days. Individual $C y$ male progeny were crossed to two en $a^{210} / \mathrm{CyO}$ virgin females. Fertile crosses were scored for absence or reduction of the $\mathrm{CyO}^{+}$progeny class and stocks were established of putative new ena alleles. Males bearing the new en $a$ mutations were mated to $w m f$ virgins at $18^{\circ} \mathrm{C}$. Spreads of polytene chromosomes stained with orecien were prepared as described (Ashburner 1989). The cytology of the following alleles was determined: ena ${ }^{G C 1}$; In $2 \mathrm{R}[55 \mathrm{~B}, 56 \mathrm{~B} 5]$; ena ${ }^{G C 5}, \operatorname{In} 2 \mathrm{R}$ [44E, 56B]; eña ${ }^{G C 7}$, In $2 \mathrm{R}$ [54DE-56B]. en $a^{G C 8}$ is a deletion that removes material distal to 56B5, uncovering ena, windbeutal, and Coracle (R. Fehon and M. Konsolaki, pers. comm.).

\section{Molecular isolation and sequencing of ena}

Genomic DNA from the AA48 P-element stock (gift of T. Laverty and G.M. Rubin, University of California, Berkeley) was cut with PstI and used for plasmid rescue. A 7-kb PstI restriction fragment was used to initiate the walk in a cosmid library (gift of Dr. J. Tamkun, University of California, Santa Cruz). A 12- to 24-hr embryonic cDNA library (Brown and Kafatos 1988) was screened with a 5.5-kb EcoRI fragment (fragment A from Fig. 1). Four independent but related cDNAs were purified in the screen. Templates were sequenced with $\left[{ }^{35} \mathrm{~S}\right] \mathrm{dATP}$ using the Sequenase 2.0 system (U.S. Biochemical). The sequences were compiled and edited using the MacVector and Assemblyalign programs (IBI). Other sequence analyses were conducted using the Genetics Computer Group software. All sequences presented were confirmed by sequencing the reverse strand. Data bases were searched using the FASTA program.

Fusion proteins and SH3-binding assays

pHisena ${ }^{53-503}$ was produced by ligating a $1.3-\mathrm{kb}$ PstI fragment of ena (bases 568-1909) into the PstI site of pQE31 (Qiagen). pHisena ${ }^{53-441}$, pHisena $a^{53-345}$, and pHisena ${ }^{53-235}$ were generated by first digesting pHisen $a^{53-503}$ with HindIII, which is present in the PQE31 polylinker $3^{\prime}$ to the PstI site, and then with NcoI (441), SauI (345), or NaeI (235). For GST fusions, cultures were lysed in a nitrogen cell disruption chamber and the proteins bound to glutathione-Sepharose (Pharmacia) essentially as described (Smith and Johnson 1988). For His-tagged proteins, cultures were lysed in $6 \mathrm{M}$ guanidine- $\mathrm{HCl}$ and fusion proteins purified by affinity to Ni-NTA agarose (Qiagen) as recommended the manufacturer.

For in vitro $\mathrm{SH} 3$ binding experiments, fusion proteins were fractionated on $10 \%$ SDS-PAGE gels and transferred to nitrocellulose as described (Harlow and Lane 1988). The binding assays were conducted as described (Olivier et al. 1993).

\section{Generation and purification of ena antibodies}

DNA fragments encoding amino acids 55-235 (ena amino-terminal) and 491-684 (ena carboxy-terminal) were subcloned into the pQE-30 and pQE-32 expression vectors (Qiagen) to generate ena fusion proteins preceded by 6 histidine residues. Fusion proteins were induced and purified from bacterial lysates by chromatography on nickel affinity columns as recommended by the manufacturer. Rabbits were immunized with $250 \mu \mathrm{g}$ of amino- or carboxy-terminal fusion proteins and boosted every 4 weeks with $250 \mu \mathrm{g}$ of antigen. Specific antibodies were purified from immune serum by affinity chromatography over immobilized antigen columns as described (Robbins et al. 1984).

\section{Immunoprecipitations and Western blot analysis}

For immunoprecipitations, S2 cells were lysed at $1 \times 10^{7} \mathrm{cells} / \mathrm{ml}$ in IP buffer [0.5\% NP-40, $150 \mathrm{~mm} \mathrm{NaCl}, 50 \mathrm{~mm}$ Tris-Cl (pH 8.0), 
5 mMEDTA] containing $1 \mathrm{~mm} \mathrm{Na} \mathrm{VO}_{4}, 1 \mathrm{~mm}$ Pefabloc (Boehringer Mannheim), and $1 \mu \mathrm{g} / \mathrm{ml}$ each of aprotinin, leupeptin, and aprotinin. For immunoprecipitations from pupae or embryos, 20 pupae or $\sim 0.05 \mathrm{ml}$ of embryos were homogenized in 1 $\mathrm{ml}$ of IP buffer containing $0.1 \%$ SDS. Samples were lysed on ice for $30 \mathrm{~min}$, cell debris was pelleted for $20 \mathrm{~min}$ at $4^{\circ} \mathrm{C}$ in a microcentrifuge, and lysates were precleared with preimmune $\mathrm{Ig}$ for $45 \mathrm{~min}$ at $4^{\circ} \mathrm{C}$. For ena or Abl immunoprecipitations, lysates were incubated with $2.5 \mu \mathrm{g}$ of specific antibody for $4 \mathrm{hr}$ at $4^{\circ} \mathrm{C}$. Immune complexes were collected with protein A (Pierce)-agarose, washed three times with IP buffer, and boiled in SDS sample buffer (Laemmli 1970). Immunoprecipitates were resolved on $7.5 \%$ SDS-polyacrylamide gels and transferred to PVDF membranes (Immobilon-P, Millipore Corporation) in $10 \mathrm{mM}$ CHES (pH 9.6), 10\% ethanol. Filters were blocked with 5\% BSA in TBST [ $50 \mathrm{~mm}$ Tris-Cl (pH 8.0), $150 \mathrm{~mm} \mathrm{NaCl}, 0.05 \%$ Tween 20]. For ena Western blots, filters were incubated with primary antibody at $0.5 \mu \mathrm{g} / \mathrm{ml}$, washed with TBST, then incubated with HRP-conjugated secondary antibodies and developed by ECL (Amersham). Western blots with $\mathrm{Abl}$ antibodies were performed as above, except the Ig concentration was $0.15 \mu \mathrm{g} / \mathrm{ml}$. Phosphotyrosine was detected using monoclonal antibody 4G10 /Upstate Biotechnology/ at $1 \mu \mathrm{g} / \mathrm{ml}$. For quantitative Western analysis, samples were serially diluted to determine a linear range for densitometry.

\section{Immune-complex kinase assays}

Immunoprecipitates were prepared as described above except that immune complexes were washed twice with IP buffer and once with kinase buffer [20 mM PIPES (pH 6.9), $10 \mathrm{~mm} \mathrm{MgCl}_{2}$, $10 \mathrm{~mm} \mathrm{MnCl}_{2}, 1 \mathrm{mM}$ DTT, $1 \mu \mathrm{M}$ ATP]. Samples were then suspended in $20 \mu \mathrm{l}$ of kinase buffer containing $10 \mu \mathrm{Ci}\left[\gamma^{32} \mathrm{P}\right] \mathrm{ATP}$ and $5 \mu \mathrm{g}$ of acid-denatured enolase. Bacterially produced ena protein (amino acids 53-503) was eluted from Ni-NTA beads in $0.5 \mathrm{M}$ imidazole, and supernatants containing $5 \mu \mathrm{g}$ of ena protein were added to the kinase reactions, which were then incubated at $30^{\circ}$ for $1 \mathrm{hr}$. Samples were resolved on $7.5 \%$ SDS gels, the gels were fixed, Coomassie stained, and dried, and phosphorylated proteins were detected by autoradiography.

\section{Phosphoamino acid analysis}

Drosophila S2 cells $\left(5 \times 10^{7}\right)$ labeled with carrier-free $\left[{ }^{32} \mathrm{P}\right]$ orthophosphate (ICN) were harvested and ${ }^{32} \mathrm{P}$-labeled ena protein was immunoprecipitated as described above. Immunoprecipitates were resolved on SDS-PAGE and transferred to an Immobilon-P membrane. The ${ }^{32} \mathrm{P}$-labeled ena protein band was excised and hydrolyzed by incubation in $6 \mathrm{M} \mathrm{HCl}$ at $110^{\circ} \mathrm{C}$ for $1 \mathrm{hr}$. Hydrolysates were lyophilized and suspended in $10 \mu l$ of water containing $1 \mathrm{mg} / \mathrm{ml}$ of phosphoserine, phosphothreonine, and phosphotyrosine standards (Calbiochem). The samples were applied to 0.1-mm-thick cellulose plates, resolved by two-dimensional thin-layer electrophoresis (Cooper et al. 1983), and stained with ninhydrin, and the labeled phosphoamino acids were detected by autoradiography.

\section{HRP immunocytochemistry and sectioning of immunostained embryos}

Canton-S embryos staged from 0 to $18 \mathrm{hr}$ were fixed and stained for antibody against ena using modifications of published procedures (Patel et al. 1987). Rabbit anti-ena polyclonal antibody was used to detect ena. Mouse monoclonal anti- $\beta$-galactosidase (Promega) antibody was used to detect $l a c Z$ expression from enhancer-trap-containing balancer chromosomes to distinguish ena null embryos from their sibs having $\mathrm{ena}^{+}$balancer chromosomes. ena mutant embryos were generated from crosses of ena $a^{G C 1} /$ CyolacZ or ena $a^{G C 5} /$ CyolacZ to ena $a^{G C 8} /$ CyolacZ. BP102 was used to detect the CNS axons. After staining with Streptavidin-horseradish peroxidase, some ena ${ }^{G C 1} / e^{\text {ena }}{ }^{G C 8} \mathrm{em}$ bryos were embedded in LR White. Cross sections of $6 \mu \mathrm{m}$ were cut and mounted on glass slides.

\section{Acknowledgments}

We thank Dr. Stephen Feller, Rockefeller University, for GSTSH3 reagents, innumerable discussions, and excellent advice. We also thank Drs. Karin Immerglück and J. Michael Bishop for the Drosophila fer cDNA and antibodies, Dr. Paul Olivier for Sos fusion proteins, Drs. Andrei Goga and Owen Witte for the human Abl constructs, and Dr. Jon Cooper for the Dsrc cDNA and antibody. We thank Dr. G.M. Rubin and the Drosophila Genome Center (funded by the National Institutes of Health (NIH) and Howard Hughes Medical Institute) for P-element line AA48. This work was supported by CA 49582 to F.M.H. and Cancer Center Core grant 07175. Postdoctoral fellowship support was provided by the American Cancer Society (to F.G.) and NIH postdoctoral training grant CA09681 (for A.R.C. and S.M.A.). Eric C. Liebl was a Damon Runyon-Walter Winchell Foundation Cancer Research Fund postdoctoral fellow. F.M.H. is a recipient of a Faculty Research Award from the American Cancer Society.

The publication costs of this article were defrayed in part by payment of page charges. This article must therefore be hereby marked "advertisement" in accordance with 18 USC section 1734 solely to indicate this fact.

\section{Note added in proof}

The sequence data for ena have been deposited to the GenBank data library under accession no. U21123. Since acceptance of this paper, two sequences with similarity to ena have appeared in the data base. Human (Z46389) and canine (Z46388) vasodilator-stimulated phospoproteins (VASPs) share sequence similarity with ena in three domains: (1) the first 113 amino acids; (2) the proline-rich central domain; and (3) the 35 amino acids at the carboxyl terminus that are required for localization of VASP to focal adhesions.

\section{References}

Andoniou, C.E., C.B.F. Thien, and W.Y. Langdon. 1994. Tumour induction by activated abl involves tyrosine phosphorylation of the product of the cbl oncogene. EMBO \%. 13: 45154523.

Ashburner, M. 1989. Drosophila: A laboratory manual. Cold Spring Harbor Laboratory Press, Cold Spring Harbor, New York

Bar-Sagi, D., D. Rotin, A. Batzer, V. Mandiyan, and J. Schlessinger. 1993. SH3 domains direct cellular localization of signaling molecules. Cell 74: 83-91.

Baskaran, R., M.E. Dahmus, and J.Y.J. Wang. 1993. Tyrosine phosphorylation of mammalian RNA polymerase II carboxy-terminal domain. Proc. Natl. Acad. Sci. 90: 1116711171.

Ben-Neriah, Y. and D. Baltimore. 1986. Structural modification of c-Abl in lymphoma and leukemia. Curr. Topics Microbiol. Immunol. 132: 82-89.

Bennett, R.L. and F.M. Hoffmann. 1992. Increased levels of the Drosophila Abelson tyrosine kinase in nerves and muscles: 
Subcellular localization and mutant phenotypes imply a role in cell-cell interactions. Development 116: 953-966.

Brand, A.H. and N. Perrimon. 1993. Targeted gene expression as a means of altering cell fates and generating dominant phenotypes. Development 118: 401-415.

Brown, N. and F. Kafatos. 1988. Functional Drosophila cDNA libraries from Drosophila embryos. J. Mol. Biol. 203: 425437.

Cheng, G., Z.-S. Ye, and D. Baltimore. 1994. Binding of Bruton's tyrosine kinase to fyn, lyn or hck through a Src homology 3 domain-mediated interaction. Proc. Natl. Acad. Sci. 91: 8152-8155.

Cooper, J.A., B.M. Sefton, and T. Hunter. 1983. Detection and quantification of phosphotyrosine in proteins. In Methods Enzymol. 99: 387-402.

Elkins, T., K. Zinn, L. McAllister, F.M. Hoffmann, and C.S. Goodman. 1990. Genetic analysis of a Drosophila neural cell adhesion molecule: Interaction of fasciclin I and Abelson tyrosine kinase mutations. Cell 60: 565-575.

Feller, S.M., B. Knudsen, and H. Hanafusa. 1994. c-Abl kinase regulates the protein binding activity of c-Crk. EMBO J. 13: 2341-2351.

Gertler, F.B., R.L. Bennett, M.J. Clark, and F.M. Hoffmann. 1989. Drosophila abl tyrosine kinase in embryonic CNS axons: A role in axonogenesis is revealed through dosage-sensitive interactions with disabled. Cell 58: 103-113.

Gertler, F.B., K.K. Hill, M.J. Clark, and F.M. Hoffmann. 1993. Dosage-sensitive modifiers of Drosophila abl tyrosine kinase function: Prospero, a regulator of axonal outgrowth, and disabled, a novel tyosine kinase substrate. Genes \& Dev. 7: 441-453.

Gertler, F.B., J.S. Doctor, and F.M. Hoffmann. 1990. Genetic suppression of mutations in the Drosophila abl proto-oncogene homolog. Science 248: 857-860.

Gout, I., R. Dhand, I.D. Hiles, M.J. Fry, G. Panayotou, P. Das, O. Truong, N.F. Totty, J. Hsuan, G.W. Booker, I.D. Campbell, and M.D. Waterfield. 1993. The GTPase dynamin binds to and is activated by a subset of SH3 domains. Cell 75: 25-36.

Harlow, E. and D. Lane. 1988. Antibodies: A laboratory manual. Cold Spring Harbor Laboratory Press, Cold Spring Harbor, New York.

Henkemeyer, M.J., F.B. Gertler, W. Goodman and F.M. Hoffmann. 1987. The Drosophila Abelson proto-oncogene homolog: Identification of mutant alleles that have pleiotropic effects late in development. Cell 51: 821-828.

Henkemeyer, M.J., R.L. Bennett, F.B. Gertler and F.M. Hoffmann. 1988. DNA sequence, structure, and tyrosine kinase activity of the Drosophila melanogaster Abelson proto-oncogene homolog. Mol. Cell. Biol. 8: 843-853.

Henkemeyer, M., S.R. West, F.B. Gertler, and F.M. Hoffmann. 1990. A novel tyrosine kinase-independent function of Drosophila abl correlates with proper subcellular localization. Cell 63: 949-960.

Hoffmann, F.M. 1991. Drosophila abl and genetic redundancy in signal transduction. Trends Genet. 7: 351-355.

Kipreos, E.T. and J.Y. Wang. 1992. Cell cycle-regulated binding of c-Abl tyrosine kinase to DNA. Science 256: 382-385.

Kloetzer, W., R. Kurzrock, L. Smith, M. Talpaz, M. Spiller, J. Gutterman, and R.B. Arlinghaus. 1985. The human cellular abl gene product in the chronic myelogenous leukemia cell line has an associated tyrosine protein kinase activity. $\mathrm{Vi}$ rology 140: 230-238.

Konopka, J.B., S.M. Watanabe, and O.N. Witte. 1985. An alteration of the human c-abl protein in K562 leukemia cells unmasks associated tyrosine kinase activity. Cell 37: 10351042.
Laemmli, U.K. 1970. Cleavage of structural proteins during the assembly of the head of bacteriophage T4. Nature 227: 680685.

Liu, J., M. Campbell, J.Q. Guo, D. Lu, Y.M. Xian, B.S. Andersson, and R.B. Arlinghaus. 1993. BCR-ABL tyrosine kinase is autophosphorylated or transphosphorylates p160 BCR on tyrosine predominantly within the first $\mathrm{BCR}$ exon. Oncogene 8: 101-109.

Matsuguchi, T., R. Salgia, M. Hallek, M. Eder, B. Druker, T.J. Ernst, and J.D. Griffin. 1994. Shc phosphorylation in myeloid cells is regulated by granulocyte macrophage colony-stimulating factor, interleukin-3, and steel factor and is constitutively increased by p210BCR/ABL. J. Biol. Chem. 269: 50165021.

McWhirter, J.R. and J.Y.J. Wang. 1991. Activation of tyrosine kinase and microfilament-binding functions of $\mathrm{c}-\mathrm{abl}$ by bcr sequences in bcr/abl fusion proteins. Mol. Cell. Biol. 11: $1553-1565$.

1993. An actin-binding function contributes to transformation by the Bcr-Abl oncoprotein of Philadelphia chromosome-positive human leukemias. EMBO I. 12: 1533-1546.

Olivier, J.P., T. Raabe, M. Henkemeyer, B. Dickson, G. Mbamalu, B. Margolis, J. Schlessinger, E. Hafen, and T. Pawson. 1993. A Drosophila SH2-SH3 adaptor protein implicated in coupling the sevenless tyrosine kinase to an activator of ras guanine nucleotide exchange, Sos. Cell 73: 171-179.

Panchamoorthy, G., T. Fukazawa, L. Stolz, G. Payne, K. Reedquist, S. Shoelson, Z. Songyang, L. Cantley, C. Walsh, and H. Band. 1994. Physical and functional interactions between $\mathrm{SH} 2$ and $\mathrm{SH} 3$ domains of the src family protein tyrosine kinase p59fyn. Mol. Cell. Biol. 14: 6372-6385.

Patel, N.H., P.M. Snow, and C.S. Goodman. 1987. Characterization and cloning of fasciclin III: A glycoprotein expressed on a subset of neurons and axon pathways in Drosophila. Cell 48: 975-988.

Pendergast, A.M., A.J. Muller, M.H. Havlik, R. Clark, F. McCormick, and O.N. Witte. 1991. Evidence for regulation of the human Abl tyrosine kinase by a cellular inhibitor. Proc. Natl. Acad. Sci. 88: 5927-5931.

Pendergast, A.M., L.A. Quilliam, L.D. Cripe, C.H. Bassing, Z. Dai, N. Li, A. Batzer, K.M. Rabun, C.J. Der, J. Schlessinger, and M.L. Gishizky. 1993. BCR-ABL-induced oncogenesis is mediated by direct interaction with the $\mathrm{SH} 2$ domain of the GRB2 adaptor protein. Cell 75: 175-185.

Pleiman, C.M., W.M. Hertz and J.C. Cambier. 1994. Activation of phosphatidylinositol-3' kinase by Src-family kinase $\mathrm{SH} 3$ binding to the p85 subunit. Science 263: 1609-1612.

Puil, L., J. Liu, G. Gish, G. Mbamalu, D. Bowtell, P.G. Pelicci, R. Arlinghaus, and T. Pawson. 1994. Bcr-Abl oncoproteins bind directly to activators of the Ras signalling pathway. EMBO $I$. 13: 764-773.

Ren, R., B.J. Mayer, P. Cicchetti and D. Baltimore. 1993. Identification of a ten-amino acid proline-rich $\mathrm{SH} 3$ binding site. Science 259: 1157-1161.

Ren, R., Z.-S. Ye, and D. Baltimore. 1994. Abl protein-tyrosine kinase selects the Crk adapter as a substrate using SH3-binding sites. Genes \& Dev. 8: 783-795.

Reuther, G.W., H. Fu, L.D. Cripe, R.J. Collier, and A.M. Pendergast. 1994. Association of the protein kinases c-bcr and bcr-abl with proteins of the 14-3-3 family. Science 266: 129133.

Robbins, A., W.S. Dynan, A. Greenleaf, and R. Tjian. 1984. Affinity-purified antibody as a probe of RNA polymerase II subunit structure. J. Mol. Appl. Genet. 2: 343-353.

Sawyers, C.L., J. McLaughlin, A. Goga, M. Havlik, and O. Witte. 1994. The nuclear tyrosine kinase c-abl negatively regulates 
cell growth. Cell 77: 121-131.

Schwartzberg, P.L., A.M. Stall, J.D. Hardin, K.S. Bowdish, T. Humaran, S. Boast, M.L. Harbison, E.J. Robertson, and S.P. Goff. 1991. Mice homozygous for the $\mathrm{abl}^{\mathrm{ml}}$ mutation show poor viability and depletion of selected $B$ and $T$ cell populations. Cell 65: 1165-1175.

Shtivelman, E., B. Lifshitz, R.P. Gale, and E. Canaani. 1985. Fused transcript of abl and bcr genes in chronic myelogenous leukemia. Nature 315: 550-554.

Simon, M.A., G.S. Dodson, and G.M. Rubin. 1993. An SH3-SH2SH3 protein is required for p21Rasl activation and binds to Sevenless and Sos proteins in vitro. Cell 73: 169-177.

Smith, D.B. and K.S. Johnson. 1988. Single-step purification of polypeptides expressed in Escherichia coli as fusions with glutathione-S transferase. Gene 67: 31-40.

Songyang, Z., S.E. Shoelson, M. Chaudhuri, G. Gish, T. Pawson, W.G. Haser, F. King, T. Roberts, S. Ratnofsky, R.J. Lechleider, B.G. Neel, R.B. Birge, J.E. Fajardo, M. Chou, H. Hanafusa, B. Schaffhausen, and L.C. Cantley. 1993. SH2 domains recognize specific phosphopeptide sequences. Cell 72: 767-778.

Tauchi, T., G.-S. Feng, R. Shen, H.Y. Song, D. Donner, T. Pawson, and H.E. Broxmeyer. 1994. SH2-containing phosphotyrosine phosphatase Syp is a target of p210bcr-abl tyrosine kinase. I. Biol. Chem 269: 15381-15387.

Tybulewicz, V.L.J., C.E. Crawford, P.K. Jackson, R.T. Bronson, and R.C. Mulligan. 1991. Neonatal lethality and lymphonemia in mice with a disruption of the c-abl proto-oncogene. Cell 65: 1153-1163.

Van Etten, R.A., P. Jackson, and D. Baltimore. 1989. The mouse type IV c-abl gene product is a nuclear protein, and activation of transforming ability is associated with cytoplasmic localization. Cell 58: 669-678.

Van Etten, R.A., P.K. Jackson, D. Baltimore, M.C. Sanders, P.T. Matsudaira, and P.A. Janmey. 1994. The $\mathrm{COOH}$ terminus of the c-Abl tyrosine kinase contains distinct F- and Gactin binding domains with bundling activity. $/$. Cell Biol. 124: 325-340.

Wang, J.Y.J. 1993. Abl tyrosine kinase in signal transduction and cell-cycle regulation. Curr. Opin. Genet. Dev. 3: 35-43.

Welch, P.J. and J.Y.J. Wang. 1993. A C-terminal protein binding domain in the retinoblastoma protein regulates nuclear $\mathrm{c}-\mathrm{abl}$ tyrosine kinase in the cell cycle. Cell 75: 779-790.

Weng, Z., S.M. Thomas, R.J. Rickles, J.A. Taylor, A.W. Brauer, C. Seidel-Dugan, W.M. Michael, G. Dreyfuss, and I.S. Brugge. 1994. Identification of Src, Fyn, and Lyn SH3 binding proteins: Implications for a function of SH3 domains. Mol. Cell. Biol. 14: 4509-4521.

Wetzler, M., M. Talpaz, R.A. Van Etten, C. Hirsch-Ginsberg, M. Beran, and R. Kurzrock. 1994. Subcellular localization of Bcr, $\mathrm{Abl}$, and Bcr-Abl proteins in normal and leukemic cells and correlation of expression with myeloid differentiation. $/$. Clin. Invest. 92: 1925-1939. 


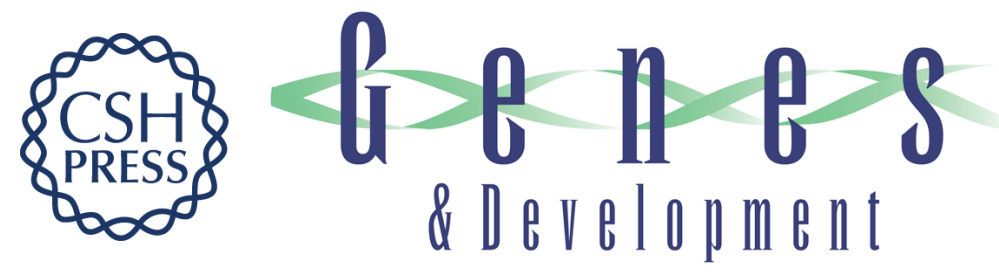

\section{enabled, a dosage-sensitive suppressor of mutations in the Drosophila Abl tyrosine kinase, encodes an Abl substrate with $\mathrm{SH} 3$ domain-binding properties.}

F B Gertler, A R Comer, J L Juang, et al.

Genes Dev. 1995, 9:

Access the most recent version at doi:10.1101/gad.9.5.521

References This article cites 52 articles, 19 of which can be accessed free at: http://genesdev.cshlp.org/content/9/5/521.full.html\#ref-list-1

License

Email Alerting Service

Receive free email alerts when new articles cite this article - sign up in the box at the top right corner of the article or click here.

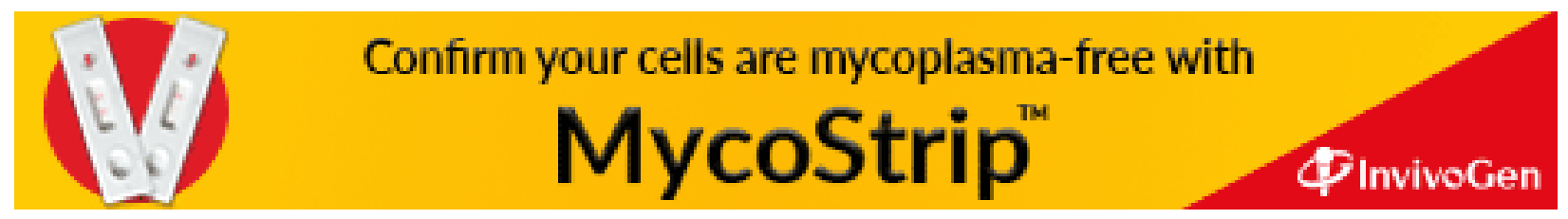

